\title{
Oxidative stress and low molecular weight antioxidants in triticale shoots under chloride salinization
}

\author{
(C) Viktor V. Ivanishchev \\ Department of Biology and Technologies of Living Systems. Tula State Lev Tolstoy \\ Pedagogical University. Lenin Ave., 125. Tula, 300026. Russia. \\ Phone:+7 (4872)65-78-08.E-mail: avdey_VV@mail.ru
}

Keywords: triticale, shoots, chloride stress, photosynthesis, principal component analysis, cluster analysis.

\begin{abstract}
We studied the alterations in oxidative stress indicators (hydrogen peroxide, superoxide radical, lipid peroxidation - LPO) and the alterations in the content of low molecular weight metabolites (ascorbic acid, glutathione, proline, chlorophyll and carotenoids) in the shoots of triticale (Triticosecale) under short-term (0$96 \mathrm{~h})$ sodium chloride stress $(120 \mathrm{mM})$ with statistical methods: principal component analysis (PCA) and cluster analysis. An analysis of the alterations in oxidative stress indicators allowed us to calculate the correlation coefficients for the pairs: peroxide - superoxide (0.52), peroxide - LPO (0.62), superoxide - LPO (0.23). The inclusion in the analysis of data on alterations in the content of low molecular weight antioxidants showed that the PCA method forms three main groups for all the studied characteristics: (1) LPO and hydrogen peroxide, (2) chlorophyll and carotenoids, (3) glutathione and ascorbate. The correlation coefficients were calculated for pairs: ascorbate - glutathione $(0.71)$, ascorbate - proline $(0.81)$, glutathione - proline (0.28). Such a value of the coefficient of the first pair suggests that ascorbic acid also performs numerous other functions, in addition to participating in the ascorbate-glutathione cycle. The high correlation between ascorbate and proline can be explained by the similar nature of alterations in their content in triticale shoots under conditions of short-term sodium chloride stress. Negative correlation coefficients in pairs of hydrogen peroxide - chlorophyll (-0.73), peroxide - carotenoids (-0.75), ascorbic acid - LPO (-0.70), LPO - proline (0.69) give reason to talk about the possible protective role of photosynthesis pigments from accumulating hydrogen peroxide, as well as the potential role of ascorbic acid and proline in protecting membranes from lipid peroxidation. The application of the cluster analysis method showed that first and second order clusters between ascorbate, proline and glutathione reflect their known antioxidant role. The results obtained may also indicate that pigments have a much lower protective function.
\end{abstract}

\section{References}

[1] V.V. Ivanishchev. About the mechanisms of plant resistance to salt and specificity of salinization influence. Proceedings of TulSU. Natural Sciences. 2019. Iss.4. P.74-88. (russian)

[2] M. Torabi. Physiological and biochemical responses of plants to salt stress. The 1st Intern Conf on New Ideas in Agricultural. Islamic Azad University Khoragsan Branch. 26-27 jan 2014. Isfahan, Iran. 2014. 25 p. https://www.semanticscholar.org/paper/PHYSIOLOGICAL-ANDBIOCHEMICAL-RESPONSESOF-PLANTSTorabi/f8867445eae6156a0e16ef13f2c74e6c836be7e9\#citing-papers.

[3] H. Jian, J. Wang, T. Wang et al. Identification of rapeseed microRNAs involved in early stage seed germination under salt and drought stresses. Frontiers in plant science. 2016. Vol.7. P.658. doi: 10.3389/fpls.2016.00658.

[4] V.V. Ivanishchev, and N.N. Zhukov. Manifestations of oxidative stress in sprouts of triticale under condition of short-term exposure of sodium chloride. Butlerov Communications. 2017. Vol.52. No.11. P.123-130. DOI: 10.37952/ROI-jbc-01/17-52-11-123

[5] V.V. Ivanishchev. On the possibility of an applying the method of cluster analysis to results of physiological-biochemical investigation of plants. Proceedings of TulSU. Natural Sciences. 2018. Iss.1. P.69-77. (russian)

[6] V.V. Ivanishchev. Investigation of the effect of short-term salt stress with the method of cluster analysis. Butlerov Communications. 2018. Vol.54. No.4. P.134-139. DOI: 10.37952/ROI-jbc-01/18-54-4-134 
[7] V.V. Ivanishchev. On application of statistical methods in stress physiology and breeding of plants.. The Bulletin of Kharkiv National Agrarian University. Series Biology. 2018. Iss.3 (45). P.111-118. https://doi.org/10.35550/vbio2018.03.111.

[8] V.V. Ivanishchev. The application of principal component analysis and cluster analysis to research of vetch seed germination in the presence of nickel chloride in the medium. Butlerov Communications. 2018. Vol.56. No.10. P.149-155. DOI: 10.37952/ROI-jbc-01/18-56-10-149

[9] V.V. Ivanishchev. The effect of nickel chloride on the relationship between oxidative stress indicators of vetch shoots. Biogeochemistry - the scientific basis for sustainable development and preservation of human health: In 2 volumes. Tula: TSPU im. L.N. Tolstoy. 2019. Vol.1. P.273-276. (russian)

[10] V.V. Ivanishchev. The application of statistical methods to indicators of triticale photosynthesis under chloride stress. Butlerov Communications. 2020. Vol.61. No.3. P.105-111. DOI: 10.37952/ROI-jbc01/20-61-2-3-105

[11] A.R. Garifzyanov, N.N. Zhukov, Yu.O. Pantyukhin, V.V. Ivanishchev. Features of NaCl-induced oxidative stress and dynamics of antioxidant enzyme activity in winter triticale organs. Reports of RAAS. 2012. Vol.2. P.9-11. (russian)

[12] A.R. Garifzyanov, N.N. Zhukov. The effect of sodium chloride salinity on the content of ascorbateglutathione cycle components in the organs of triticale. Proceedings of TulSU. Natural Sciences. 2012. Iss.3. P.165-174. (russian)

[13] N.N. Bureeva. Multidimensional statistical analysis with an application of "Statistics" software package. Nyzhnii Novgorod: NNSU. 2007. 112p. (russian)

[14] Yu.E. Kolupaev. The reactive oxygen species in plants under the action of stressors: the formation and possible functions. The Bulletin of Kharkiv National Agrarian University. Series Biology. 2007. Vol.3. No.12. P.6-26. (russian)

[15] A.R. Garyfzyanov, N.N. Zhukov, V.V. Ivanishchev. Formation and physiological reactions of oxygen active forms in plant cells. Modern problems of science and education. 2011. Vol.2. 21p. https://elibrary.ru/download/elibrary_16903824_79256112.pdf. (russian)

[16] Yu.E. Kolupaev, T.O. Yastreb. The physiological function of non-enzymatic antioxidants of plants. The Bulletin of Kharkiv National Agrarian University. Series Biology. 2015. Vol.2. Iss.35. P. 6-25.

[17] G.N. Chupakhina. The system of ascorbic acid in plants: monograph. Kaliningrad: Kaliningrad. Univ. 1997. 120p. (russian) 